\section{For precise, effective cleaning}
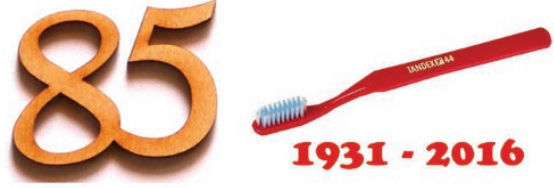

Drop by stand Q30 at BDIA Dental Showcase and meet the team from Tandex.

Tandex has everything your patients need for precise and effective cleaning. The SOLO brush features a unique design to reach all the critical areas. It can be used with implants and orthodontic appliances, with a small head and angled neck for easy access.

The SOLO is complemented by the FLEXI interdental brush, which comes in nine different sizes to suit all spaces. Also part of the range is the PROXI, an interdental brush comprising of a metal tip enclosed by a plastic head. This means no risk to tissue. Both the FLEXI and PROXI can be used with Tandex GEL, which is non-abrasive and contains $0.2 \%$ sodium fluoride.

With over 80 years' experience in producing premium quality dental products, Tandex will be your partner in helping your patients achieve optimal oral hygiene. Come and find out for yourself at BDIA Dental Showcase, held this year at London's ExCeL. www.tandex.dk

\section{A whole host of offers}

VOCO presents several very remarkable novelties at BDIA Dental Showcase, such as Admira Fusion, the world's first restorative material to combine ORMOCER with nanohybrid technology. In this case, both the fillers and the matrix are based on silicon oxide. Thanks to this 'pure silicate technology', Admira Fusion boasts excellent biocompatibility, extremely low shrinkage, optimal colour stability and a high filler content. The new filling system is complemented by Admira Fusion x-tra, which allows increments of up to $4 \mathrm{~mm}$ while displaying the same physical properties, and by Admira Fusion Flow, which features excellent flow properties with complete wetting of cavity walls. Admira Fusion, Admira Fusion x-tra and Admira Fusion Flow are compatible with all conventional bonding agents.

Ionolux is a light-curing, glass-ionomer restorative material in the innovative VOCO application capsules. One of the characteristics of Ionolux is that the point in time at which it starts setting can be determined by light-curing. Application of Ionolux is quick, and the material can be modelled with ease without sticking to the instrument. It also adapts excellently to cavity walls. Ionolux not only makes conditioning of the dental hard tissue unnecessary, there is also no need to apply a final coat of varnish. Polymerisation times are short and practice-oriented, at 20 seconds per $2 \mathrm{~mm}$ layer. Ionolux is easy to polish, it is biocompatible and releases fluorides.

Futurabond $U$ is the market's only true universal adhesive in a disposable applicator. Futurabond $\mathrm{U}$ offers practitioners an outstanding range of options for application, as much with regard to indications as to selection of the etching technique or the curing mode: self-etch, selective-etch or total-etch. This universal adhesive is fully compatible with all light-curing, dual-curing and self-curing methacrylate-based composites and is suitable for both direct and indirect restorations - and without any additional activator for dual-curing. Futurabond $U$ can also be used for desensitising hypersensitive tooth necks and after cavity preparation, and it is suitable as a protective varnish for glass-ionomer cement restorations.

VOCO will be exhibiting a whole host of offers at amazing bargain prices on stand L40. www.voco.com

\section{A toothbrush with motion sensor technology}

Dental Showcase is the number one dental show in the UK and is therefore a natural partner for Oral-B, who is once again the Headline Sponsor.

Much interest is expected in the company's new power toothbrush, Oral-B Genius. By combining motion sensor technology located in the brush, and video recognition using a smartphone's camera, all areas of the user's mouth can be tracked so that they know exactly where they've brushed and where they've missed! Patients receive instant feedback on the brushing of each zone of the mouth via the Oral-B App 4.1, including guidance on pressure applied and brushing duration.

The mechanical benefits of Oral-B's power toothbrushes complement the chemical efficacy afforded by their Pro-Expert toothpaste. It's the inclusion of stabilised stannous fluoride $\left(\mathrm{SnF}^{2}\right)$ that makes the difference. Stannous fluoride was the first scientifically recognised fluoride and has been stabilised and combined with sodium hexametaphosphate, to provide additional protection.

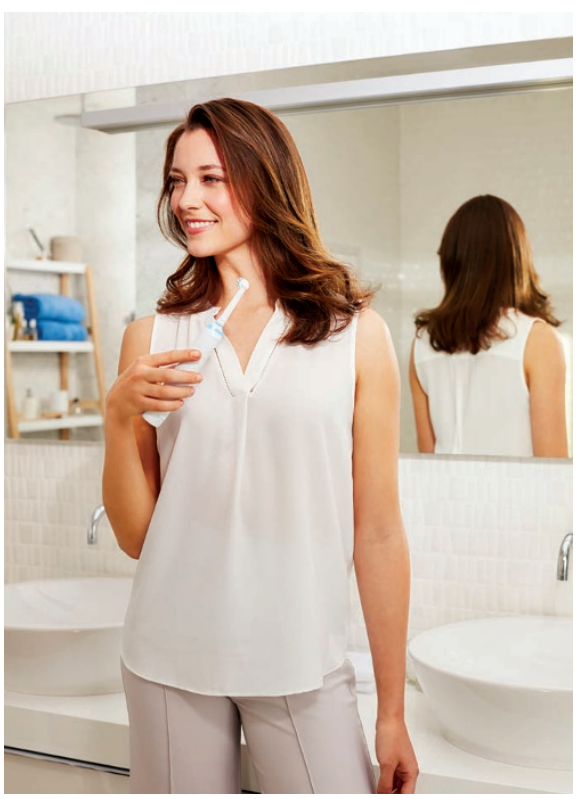

\section{A diverse range of dental materials}

Will you be attending this year's BDIA Dental Showcase? If so, you simply cannot afford to miss out on visiting stand $\mathrm{F} 60$ and talking to the $3 \mathrm{M}$ Oral Care team.

Renowned for its diverse range of dental materials, from restorative to preventative and prosthodontic - not to mention the latest addition of specialist orthodontic equipment - 3M Oral Care has everything aspiring dentists need to produce excellent results.

This is precisely what delegates to the 3M Oral Care stand will discover. The team will be at hand to discuss a wide array of products and their clinical applications, and are more than happy to answer any questions you may have.

If you only have time to visit one stand at this year's BDIA Dental Showcase, be sure it's $3 \mathrm{M}$ Oral Care's.

For more information, call 08456025094 or visit www.3Mespe.co.uk.

$3 \mathrm{M}$ is a trademark of the $3 \mathrm{M}$ Company. 